\title{
Recyclization of pyrimidine-2(1H)-one into 5-ureido-1,2-azolines
}

\author{
a Andrei Yu. Ershov, b and Natalija V. Koshmina \\ ${ }^{a}$ Institute of Macromolecular Compounds, Russian Academy of Sciences, 199004, Bolshoi \\ pr.,31, Saint Petersburg, Russia \\ ${ }^{b}$ Saint Petersburg University, 198904, Universitetsky pr., 2, Saint Petersburg, Russia \\ E-mail:ershov@hq.macro.ru
}

(received 05 Apr 00; accepted 26 Nov 00; published on the web 04 Dec 00)

\begin{abstract}
A reaction of 1-aryl-4,6-dimethylpyrimidine-2(1H)-ones with hydroxylamine and acetylhydrazine leads to previously unknown 5 - $N$-arylcarbamoylamino derivatives of 3,5-dimethyl- $\Delta^{2}$ isoxa-zoline and $-\Delta^{2}$-pyrazoline. The structure of the compounds obtained was confirmed by ${ }^{1} \mathrm{H}$ and ${ }^{13} \mathrm{C}$ NMR as well as independent synthesis by reacting phenyl isocyanate with 5 -amino-3,5dimethyl- $\Delta^{2}$-isoxazoline and -1 -acetyl- $\Delta^{2}$-pyrazoline.
\end{abstract}

Keywords: Pyrimidine-2-ones, hydroxylamine, 5-ureido-1,2-azolines

\section{Introduction}

1,3- $\mathrm{N}$-Carbamoylimine oximes (hydrazones) attract attention as potential isomeric (tautomeric) systems capable of existing in both a five-membered 1,2-azoline $\left(\Delta^{2}\right.$-iso-xazoline or $\Delta^{2}$ pyrazoline) form and six-membered pyrimidine-2(1H)-one (or -thione) form. We showed previously [1] that these compounds were obtained by combining phenyl isothiocyanate with 5amino- $\Delta^{2}$-isoxazolines and 1-acetyl-5-amino- $\Delta^{2}$-pyrazo-lines. An attempt to prepare them by an alternative route, the reaction of hydroxylamine with pyrimidine-2(1H)-thiones, led to the derivatives of pyrimidine $1-N$-oxides by Dimroth rearrangement.

On the other hand, Kashima et al. [2] and Dickinson et al. [3] showed that 1,4,6-trisubstituted pyrimidines- $2(1 H)$-ones tend to recyclize into isoxazole and pyrazole derivatives when treated with hydroxylamine and hydrazine, respectively; this indicates that the reaction proceeded by the $S_{N}$ (ANRORC) (Addition-Nucleophile-Ring Opening Ring Closure process) mechanism [4], that is, through intermediate formation of 1,3- $N$-carbamoylimine oximes (hydrazones). Therefore, we reexamined the reaction of hyd-roxylamine and acetylhydrazine with a series of 1-aryl-4,6dimethylpyrimidine-2(1H)-ones (see Scheme). 
<smiles>[R]CCn1c(C)cc([N+](=O)[O-])nc1=O</smiles>

1a-1c $\downarrow \mathrm{NH}_{2} \mathrm{XH}$<smiles>[R]OCN1C(=O)N=C(C)CC1([N])NN</smiles>

A

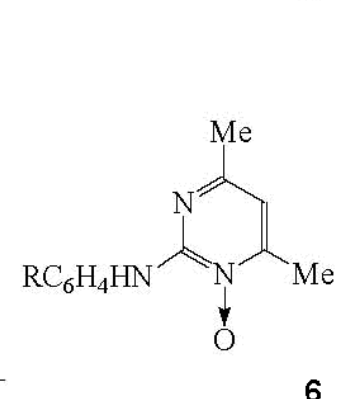<smiles></smiles><smiles>O=CO[SiH3]</smiles>

2a, 2b

$-\mathrm{H}_{2} \mathrm{O} \underset{\gamma}{\gtrless} \mathrm{RC}_{6} \mathrm{H}_{4} \mathrm{HNCONH}_{2}$

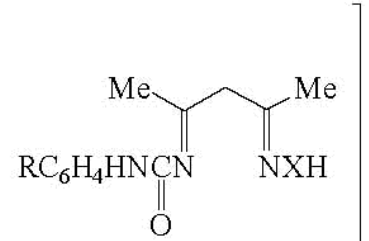

B

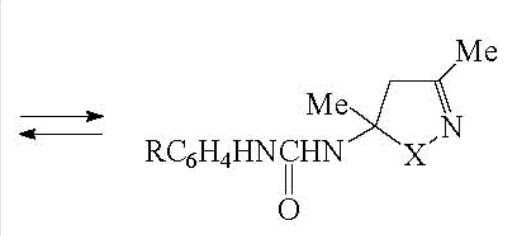

C $\quad 4 a-4 f$ $-\mathrm{RC}_{6} \mathrm{H}_{4} \mathrm{HNCONH}_{2} \downarrow$

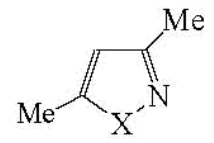

$5 a, 5 b$

Scheme 1,4. $X=O$, a $R=H$, b $R=4-M e$, c $R=4-M e O, X=N C O M e$, d $R=H$, e $R=4-M e$, f $R=4$ $\mathrm{MeO}$;

\section{Scheme 2,3,5. a $X=O$, b $X=N C O M e$}

The reaction of these compounds in methanol was found to proceed at ambient temperature in the presence of sodium hydroxide (see Experimental) to give compounds $\mathbf{4 a - 4 f}$ in good yield. According to elemental analysis data (Table 1), the composition of compounds $4 \mathbf{a}-\mathbf{4 c}$ confirmed them as the $1: 1$ products of hydroxylamine addition to the corresponding pyrimidine- $2(1 H)$-ones 1a-1c and excluded a reaction course by the Dimroth rearrangement $[1,2,5]$ to produce 2arylamino-4,6-dimethylpyrimidine $1-N$-oxides $\mathbf{6}$. We were unable to prepare compounds 4a-4f by another possible method: combining $\mathrm{N}$-arylureas with previously described [6,7] 5-hydroxy3,5-dimethyl- $\Delta^{2}$-isoxazoline $2 \mathbf{a}$ and 1 -acetyl- $\Delta^{2}$-pyrazoline $\mathbf{2 b}$. Thus, no reaction was observed at ambient temperature, but refluxing the reagents in methanol in the presence of catalytic amounts of trifluoroacetic acid led to immediate dehydration of compounds $\mathbf{2 a}, \mathbf{2} \mathbf{b}$ to afford 1,2-azoles $\mathbf{5 a}$ and $\mathbf{5 b}$.

The cyclic 1,2-azoline ( $\Delta^{2}$-isoxazoline and $\Delta^{2}$-pyrazoline) structure $\mathbf{C}$ of compounds $\mathbf{4 a - 4 f}$, rather than pyrimidine $\mathbf{A}$ and $\mathbf{D}$ or linear $\mathbf{B}$, follows from the spectral data: the presence of the typical $A B$ pattern in ${ }^{1} \mathrm{H}$ NMR spectra (Table 2) and a signal of $s p^{3}$-hybrid $\mathrm{C}^{5}$ atom in ${ }^{13} \mathrm{C}$ NMR spectra (Table 3 ). The position of the latter allows a choice of $\Delta^{2}$-isoxazoline derivatives $4 \mathbf{a}-\mathbf{4 c}$, 
$\delta_{\mathrm{C}} 92 \mathrm{ppm}\left(\mathrm{N}-\mathrm{C}-\mathrm{O}\right.$ environment), and $\Delta^{2}$-pyrazolines $4 \mathbf{d}-\mathbf{4 f}, \delta_{\mathrm{C}} 74 \mathrm{ppm}$ (N-C-N environment). We observed previously a similar upfield shift $\left(\Delta \delta_{\mathrm{C}} \sim 20 \mathrm{ppm}\right)$ for the linear analogues of hemiacetal and hemi-aminal fragments [8]. The signals in ${ }^{1} \mathrm{H}$ and ${ }^{13} \mathrm{C}$ NMR spectra of the previously studied series of 3,5-dimethyl-5-( $N$-phenylthioureido)- $\Delta^{2}$-isoxazolines and -1-acetyl$\Delta^{2}$-pyra-zolines [1] agree well with the proposed structure of compounds $\mathbf{4 a - 4 f}$.

Additional evidence for the 1,2-azoline structure $\mathbf{C}$ of compounds $\mathbf{4 a}$ and $\mathbf{4 d}$ was provided by the possibility of their preparation through independent synthesis: reaction of phenyl isocyanate with 5-amino-3,5-dimethyl- $\Delta^{2}$-isoxazoline $\mathbf{3 a}$ and -1 -acetyl- $\Delta^{2}$-pyrazoline $3 \mathbf{b}$, which we described previously [1] (see Experimental).

Short refluxing of compounds 4a-4f in methanol in the presence of catalytic amounts of sulfuric acid was found to give quantitative yields of 3,5-dimethylisoxazole 5a and 1-acetyl-3,5dimethylpyrazole $\mathbf{5 b}$. A comparison of physico-chemical and spectral data for these compounds (see Experimental) with literature analogues $[9,10]$ confirms those structures.

Thus, the data considered, on the one hand, extends our insight into the mechanism of the pyrimidine - 1,2-azole recyclization [1-4,11] taking into account the intermediate formation of 5uredo- $\Delta^{2}$-isoxazolines and 5-uredo-1-acetyl- $\Delta^{2}$-pyrazolines, and on the other hand, demonstrates the possibility of reverse transformation in the reaction of isocyanates with 3,5-disubstituted 5amino-1,2-azolines.

\section{Experimental Section}

General Procedures. ${ }^{1} \mathrm{H}$ and ${ }^{13} \mathrm{C}$ NMR spectra were recorded on Bruker AC 200 spectrometer operating at 200 and $50.33 \mathrm{MHz}$, respectively. The purity of prepared compounds was controlled by TLC on Silufol UV 254 plates with 1:1 benzene-acetone eluent. All compounds gave satisfactory elemental analyses for $\mathrm{C}, \mathrm{H}$ and $\mathrm{N}$. Compounds 1a-1c, 2a,2b, 3a,3b,5a, and $\mathbf{5 b}$ were obtained by known procedures. Properties of the compounds obtained are in agreement with literature data $[1,2,6,7]$.

5-(3-Arylureido)-3,5-dimethyl- $\Delta^{2}$-isoxazolines $4 a-4 c$ and 5-(3-arylureido)-3,5-dimethyl-1acetyl- $\Delta^{2}$-pyrazolines $4 \mathbf{d}-\mathbf{4 f}$. Method $A$. A solution of $20 \mathrm{mmol}$ of hydroxylamine base or acetylhydrazine and $20 \mathrm{mmol}$ of sodium hydroxide in $30 \mathrm{ml}$ of methanol and $10 \mathrm{ml}$ of water was added with stirring to a solution of $10 \mathrm{mmol}$ of compound 1a-1c in $30 \mathrm{ml}$ of methanol. The mixture was kept at $25{ }^{\circ} \mathrm{C}$ for 3 days. After neutralizing it with the dilute hydrochloric acid and removing the solvent under reduced pressure, $100 \mathrm{ml}$ of water was added to the residue. The precipitate that formed was filtered off and recrystallized from an ethanol-water mixture, 1:1. Method B. A solution of $5 \mathrm{mmol}$ of compound $\mathbf{3 a}$ or $\mathbf{3 b}$ and $5 \mathrm{mmol}$ of phenyl isocyanate in 50 $\mathrm{ml}$ of chloroform was kept at $25{ }^{\circ} \mathrm{C}$ for $10 \mathrm{~h}$. After the solvent was removed under reduced pressure, the residue was washed with ether and recrystallized from an ethanol-water mixture, $1: 1$. 
3,5-Dimethylisoxazole 5a and 1-acetyl-3,5-dimethylpyrazole 5b. A mixture of $5 \mathrm{mmol}$ of compound 4a-4f, $50 \mathrm{ml}$ of methanol, and several drops of sulfuric acid was heated under reflux for $3 \mathrm{~h}$. After the solvent was removed in a vacuum, $75 \mathrm{ml}$ of ether and $25 \mathrm{ml}$ of hexane was added to the residue. The crystalline matter was filtered off, and the filtrate was concentrated under reduced pressure to give compounds $\mathbf{5 a}, \mathbf{5 b}$ in yields of 90 and $95 \%$, respectively. ${ }^{13} \mathrm{C}$ NMR spectrum of compound $5 \mathbf{a}\left(\mathrm{CDCl}_{3}, \delta_{\mathrm{C}}, \mathrm{ppm}\right): 10.8\left(\mathrm{CH}_{3}\right), 11.6\left(\mathrm{CH}_{3}\right), 101.9\left(\mathrm{C}^{4}\right), 159.4$ $\left(\mathrm{C}^{3}\right), 168.6\left(\mathrm{C}^{5}\right) .{ }^{13} \mathrm{C}$ NMR spectrum of compound $\mathbf{5 b}\left(\mathrm{CDCl}_{3}, \delta_{\mathrm{C}}, \mathrm{ppm}\right): 13.2\left(\mathrm{CH}_{3}\right), 14.0\left(\mathrm{CH}_{3}\right)$, $22.9\left(\mathrm{CH}_{3}\right), 110.7\left(\mathrm{C}^{4}\right), 143.5\left(\mathrm{C}^{5}\right), 151.5\left(\mathrm{C}^{3}\right), 170.9(\mathrm{C}=\mathrm{O})$.

Table 1. Melting points, yields and elemental analysis data for $\Delta^{2}$-isoxazolines and $\Delta^{2}$ pyrazolines $4 \mathrm{a}-4 \mathrm{f}$

\begin{tabular}{|c|c|c|c|c|c|c|}
\hline \multirow[t]{2}{*}{ Compd } & \multirow[t]{2}{*}{$\mathrm{Mp}^{\circ} \mathrm{C}$} & \multicolumn{3}{|c|}{$\begin{array}{c}\text { Found, \% } \\
\text { Calculated, \% }\end{array}$} & \multirow[t]{2}{*}{ Formula } & \multirow{2}{*}{$\begin{array}{l}\text { Yield, \% } \\
\text { (Method) }\end{array}$} \\
\hline & & $\mathrm{C}$ & H & $\mathbf{N}$ & & \\
\hline \multirow{2}{*}{$4 a$} & \multirow{2}{*}{$108-111$} & $\underline{61.83}$ & $\underline{6.81}$ & $\underline{17.97}$ & \multirow{2}{*}{$\mathrm{C}_{12} \mathrm{H}_{15} \mathrm{~N}_{3} \mathrm{O}_{2}$} & \multirow{2}{*}{$50(A) ; 70(B)$} \\
\hline & & 61.79 & 6.84 & 18.01 & & \\
\hline \multirow{2}{*}{ 4b } & \multirow{2}{*}{$173-176$} & $\underline{63.08}$ & $\underline{6.89}$ & $\underline{17.03}$ & \multirow{2}{*}{$\mathrm{C}_{13} \mathrm{H}_{17} \mathrm{~N}_{3} \mathrm{O}_{2}$} & \multirow{2}{*}{$45(A)$} \\
\hline & & 63.14 & 6.93 & 16.99 & & \\
\hline \multirow{2}{*}{$4 c$} & \multirow{2}{*}{$182-185$} & $\underline{59.27}$ & $\underline{6.48}$ & $\underline{16.02}$ & \multirow{2}{*}{$\mathrm{C}_{13} \mathrm{H}_{17} \mathrm{~N}_{3} \mathrm{O}_{3}$} & \multirow{2}{*}{$60(A)$} \\
\hline & & 59.30 & 6.51 & 15.96 & & \\
\hline \multirow{2}{*}{ 4d } & \multirow{2}{*}{$135-137$} & $\underline{61.28}$ & $\underline{6.59}$ & 20.45 & \multirow{2}{*}{$\mathrm{C}_{14} \mathrm{H}_{18} \mathrm{~N}_{4} \mathrm{O}_{2}$} & \multirow{2}{*}{$45(A) ; 75(B)$} \\
\hline & & 61.30 & 6.61 & $\overline{20.42}$ & & \\
\hline \multirow{2}{*}{ e } & \multirow{2}{*}{$215-218$} & $\underline{62.51}$ & $\underline{7.04}$ & $\underline{19.39}$ & \multirow{2}{*}{$\mathrm{C}_{15} \mathrm{H}_{20} \mathrm{~N}_{4} \mathrm{O}_{2}$} & \multirow{2}{*}{$50(A)$} \\
\hline & & 62.48 & 6.99 & 19.43 & & \\
\hline \multirow{2}{*}{ 4f } & \multirow{2}{*}{ 195-197 } & $\underline{59.22}$ & 6.58 & $\underline{18.46}$ & \multirow{2}{*}{$\mathrm{C}_{15} \mathrm{H}_{20} \mathrm{~N}_{4} \mathrm{O}_{3}$} & \multirow{2}{*}{$55(A)$} \\
\hline & & 59.19 & 6.62 & 18.41 & & \\
\hline
\end{tabular}


Table 2. ${ }^{1} \mathrm{H}$ NMR spectra of $\Delta^{2}$-isoxazolines and $\Delta^{2}$-pyrazolines $4 \mathrm{a}-4 \mathrm{f}$ in DMSO- $\mathrm{d}_{6}, \delta$, ppm $(\mathrm{J}$, $\mathrm{Hz})$

\begin{tabular}{|c|c|c|c|c|c|c|}
\hline Compd & $\begin{array}{c}\mathrm{CH}_{3} \mathrm{C}^{3}, \mathrm{~s}, \\
3 \mathrm{H}\end{array}$ & $\begin{array}{c}\mathrm{CH}_{3} \mathrm{C}^{5}, \mathrm{~s}, \\
3 \mathrm{H}\end{array}$ & $\begin{array}{c}\mathrm{R}, \\
\mathrm{s}, \\
3 \mathrm{H}\end{array}$ & $\begin{array}{c}\mathrm{H}^{4}, A B \text { pattern, } \\
2 \mathrm{H}\end{array}$ & $\mathrm{H}_{\text {arom. }}$ & $\begin{array}{c}2 \mathrm{NH}, \text { br.s, } \\
2 \mathrm{H}\end{array}$ \\
\hline $4 a$ & 1.89 & 1.58 & - & $2.81 ; 3.38(18)$ & $\begin{array}{c}6.95-7.38 \\
(5 \mathrm{H})\end{array}$ & $7.42 ; 8.44$ \\
\hline $4 b$ & 1.89 & 1.59 & 2.23 & $2.80 ; 3.39(18)$ & $\begin{array}{c}7.03-7.25 \\
(4 \mathrm{H})\end{array}$ & $7.06 ; 8.30$ \\
\hline 4c & 1.90 & 1.58 & 3.71 & $2.81 ; 3.39(18)$ & $\begin{array}{c}6.72-7.28 \\
(4 \mathrm{H})\end{array}$ & $6.71 ; 8.22$ \\
\hline $4 d^{\mathrm{a}}$ & 1.91 & 1.68 & - & $2.77 ; 3.45(19)$ & $\begin{array}{c}6.96-7.38 \\
(5 \mathrm{H})\end{array}$ & $7.46 ; 8.67$ \\
\hline $4 e^{a}$ & 1.94 & 1.67 & 2.21 & $2.78 ; 3.45(19)$ & $\begin{array}{c}7.02-7.23 \\
(4 \mathrm{H})\end{array}$ & $6.87 ; 8.51$ \\
\hline $4 \mathbf{f}^{\mathrm{a}}$ & 1.95 & 1.68 & 3.68 & $2.75 ; 3.43(18)$ & $\begin{array}{c}6.73-7.35 \\
(4 \mathrm{H})\end{array}$ & $6.73 ; 8.49$ \\
\hline
\end{tabular}

${ }^{\text {a }}$ Methyl protons of $N$-acetyl group display signals at $2.10 \mathrm{ppm}(\mathrm{s}, 3 \mathrm{H})$.

Table 3. ${ }^{13} \mathrm{C}$ NMR spectra of $\Delta^{2}$-isoxazolines and $\Delta^{2}$-pyrazolines $4 \mathrm{a}-4 \mathrm{f}$ in DMSO- $\mathrm{d}_{6}, \delta_{\mathrm{C}}, \mathrm{ppm}$

\begin{tabular}{ccccccccc}
\hline Compd & $\mathrm{CH}_{3} \mathrm{C}^{3}$ & $\mathrm{CH}_{3} \mathrm{C}^{5}$ & $\mathrm{R}$ & $\mathrm{C}^{3}$ & $\mathrm{C}^{4}$ & $\mathrm{C}^{5}$ & $\mathrm{C}=\mathrm{O}$ & $\mathrm{C}_{\text {arom }}$ \\
\hline $\mathbf{4 a}$ & 13.1 & 26.5 & - & 155.6 & 47.9 & 92.4 & 153.6 & $117.9-139.2$ \\
$\mathbf{4 b}$ & 13.1 & 26.5 & 20.4 & 155.5 & 47.9 & 92.5 & 153.6 & $118.0-137.4$ \\
$\mathbf{4 c}$ & 13.1 & 26.6 & 55.2 & 155.5 & 47.9 & 92.5 & 153.8 & $114.0-154.3$ \\
$\mathbf{4} \mathbf{d}^{\mathrm{a}}$ & 15.8 & 26.2 & - & 154.4 & 50.0 & 74.6 & 153.9 & $117.7-140.0$ \\
$\mathbf{4 e}^{\mathrm{a}}$ & 15.7 & 26.2 & 20.3 & 154.3 & 50.0 & 74.6 & 153.9 & $117.7-137.6$ \\
$\mathbf{4 f}^{\mathrm{a}}$ & 15.8 & 26.3 & 55.2 & 154.4 & 50.1 & 74.7 & 153.1 & $114.0-154.2$ \\
\hline
\end{tabular}

${ }^{\text {a }}$ Carbon atom of $N$-acetyl group display at $22.5\left(\mathrm{CH}_{3}\right)$ and $167.3 \mathrm{ppm}(\mathrm{C}=\mathrm{O})$.

\section{References}

1. Ershov, A.Yu., Zh. Org. Khim.(Russ. J. Org. Chem.), 1995, vol. 31, no. 7, p 1057.

2. Kashima, C., Katoh, A., Yokota, Y., and Omote Y., Chem. Pharm. Bull., 1981, vol. 29, no. 9, p 2516.

3. Dickinson, R.G., Jacobsen, N.W., and Gillis R.G., Aust. J. Chem., 1975, vol.28, no. 4, p 859.

4. van der Plas H.C., Khim. Geterotsikl. Soedin.(Chem. Heterocyl. Comp.), 1994, nos. 11-12, p 1649. 
5. Kashima, C., Katoh, A., Yokota, Y., and Omote Y., Chem. Pharm. Bull., 1982, vol. 30, no. 6, p 1942.

6. Escale, R., Petrus, F., and Verducci, J., Bull. Soc. Chim. Fr., 1974, nos. 3-4, p 725.

7. Yusupov, V.G., Yakimovich, S.I., Nasirdinov, S.D., and Parpiev N.A., Zh. Org. Khim. (Russ. J. Org. Chem.), 1980, vol. 16, no. 2, p 415.

8. Ershov, A.Yu., Gavrilova I.I., and Panarin E.F., Zh. Prikl. Khim. (Russ. J. Appl. Chem.), 1995, vol. 68, no. 9, p 1522.

9. Gainer, J., Howarth, G.A., Hoyle, W., and Roberts, S.M., Org. Magn. Reson., 1976, vol. 8, no. 4, p 226.

10. Begtrup, M., Claramunt, R.M., Elguero, J., J. Chem. Soc., Perkin Trans. 2, 1978, no. 2, p 99.

11. van der Plas, H.C., Vollering, M.C., Jongejan, H., and Zuurdeeg, B., Recl. Trav. Chim. Pays-Bas, 1974, vol. 93, no. 8, p 225. 